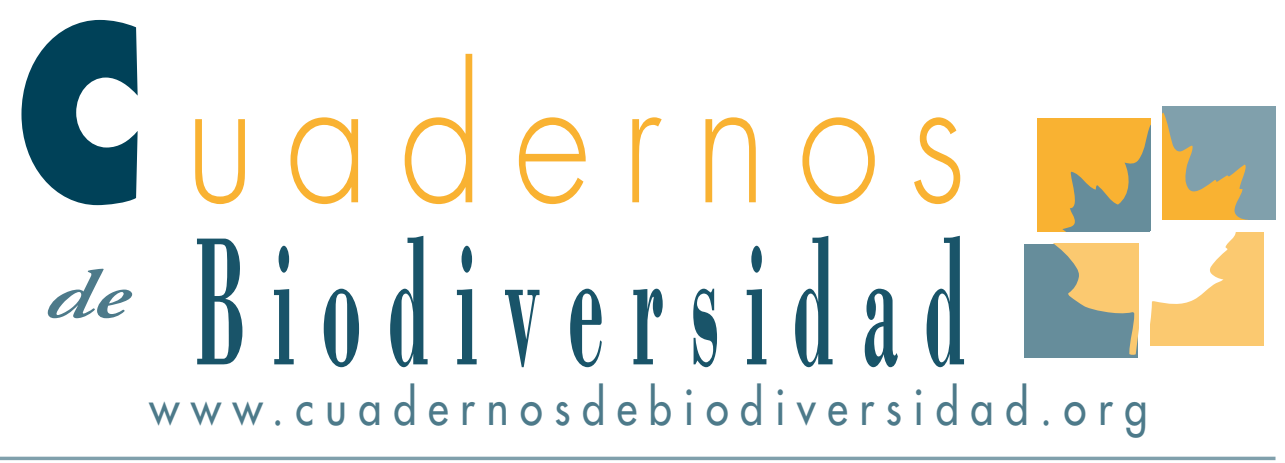

\title{
Félix de Azara y la condición de naturalista
}

\section{T. Ferrández Verdú ${ }^{1}$ y F. Almarcha Martínez ${ }^{2}$}

i Concejalía de Medio Ambiente. Ayto. de Orihuela. trinofv@gmail.com

2 Dpto. Humanidades Contemporáneas. Universidad de Alicante. Paco.almarcha@ua.es

\section{RESUMEN}

Para centrar la figura de Félix de Azara se destaca la condición de naturalista ilustrado del s. XVIII frente a la del científico. Como militar a las órdenes de la Corona española realizó una misión en la América meridional. Una vez concluidos sus trabajos, hubo de permanecer allí durante trece años, tiempo que dedica Azara al estudio sistemático de la flora y la fauna del continente americano. Sin conocimientos previos, ni bibliografía que consultar, consigue describir 448 especies de aves además de una gran cantidad de cuadrúpedos. Su obra científica y su vida como naturalista son hoy un valioso legado que se debe preservar y dar a conocer.

\section{PALABRAS CLAVE:}

Félix de Azara, naturalista español, legado científico, América meridional.

\section{ABSTRACT}

In order to approach the figure of Félix de Azara we must differentiate between his condition as an illustrated naturalist of the 18th century and his condition as a scientist. He undertook a mission in South America as a soldier under the command of the Spanish Crown. When he had finished his work, he had to stay there for thirteen years, during which Azara devoted his time to the systematic study of the flora and fauna of the American continent. Although without previous knowledge or literature to consult, he described 448 species of birds as well as numerous quadrupeds. His scientific work and his life as a naturalist are a valuable legacy that we must preserve and publicize.

\section{KEY WORDS:}

Féliz de Azara, Spanish naturalist, scientific legacy, South America. 
El María Moliner define al naturalista como aquella persona que se dedica al estudio de la Ciencias Naturales. Sin embargo, el término evoca una disposición para el conocimiento y disfrute de la naturaleza que no, forzosamente, está presente en todos los estudiosos de la naturaleza. El gusto por la belleza y el valor de lo natural, el deleite desmedido por su contemplación o la dedicación casi obsesiva a su estudio, son atributos del naturalista que no poseen, necesariamente, los profesionales de estas disciplinas científicas. Así, se trata de una categoría distinta que no siempre va unida a la del biólogo profesional. Sin embargo, especialmente en círculos académicos, el uso que se hace del término connota la falta de formación reglada sobre los múltiples aspectos de la naturaleza, por lo que se considera que el naturalista, a diferencia del científico (botánico, ecólogo, zoólogo, etc.), no ha recibido los conocimientos académicos que acrediten su formación. No obstante, si nos atenemos a su definición, no hay estrictamente ninguna acepción en la palabra que nos remita a esta carencia. El uso del término "naturalista" aplicado a los grandes investigadores de la naturaleza del s. XIX y anteriores es posiblemente el origen de esta connotación. Hombres dedicados al estudio de lo natural que no siempre tuvieron una formación académica en las disciplinas que investigaban, simplemente por no existir en los currículos académicos de la época, fueron considerados naturalistas, de ahí que el término evoque en muchos casos la imagen de aquellos primeros "científicos aficionados", aunque en ningún caso haga referencia a la calidad de sus investigaciones.

Esta breve disquisición terminológica viene al caso cuando se pretende hablar de un hombre que fue un naturalista en el sentido más genuino del término. La figura de Félix de Azara encarna a la perfección la del naturalista ilustrado del XVIII, incluida la faceta de "científico aficionado" que, sin ningún conocimiento previo, tuvo la osadía intelectual de enfrentarse al estudio y descripción de buena parte de la fauna vertebrada (aves y cuadrúpedos) de la América meridional, desde Paraguay al Río de la Plata, y realizar un gran trabajo.

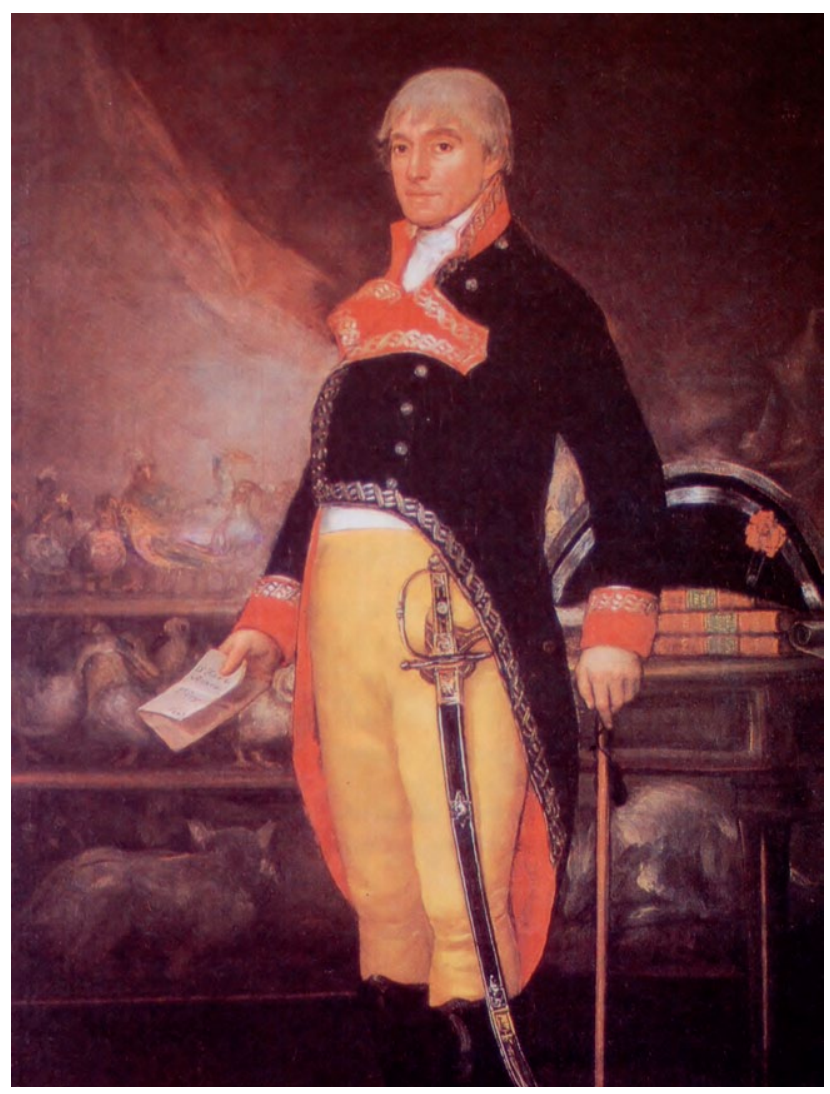

Félix de Azara retratado por Goya (Colección Ibercaja)

Con 39 años, el Capitán de Fragata Azara zarpó de Lisboa con el encargo, por parte de la Corona española, de fijarlos límites de los territorios de ultramar frente a las posesiones portuguesas de la zona, entre Paraguay y el Río de la Plata, según habían sido establecido en el Tratado de San Ildefonso de 1778 por ambos estados. Siete años le llevó al capitán Azara el establecimiento de aquellos límites y el levantamiento topográfico de sus mapas. En ocasiones definidos en el Tratado de forma imprecisa y otras directamente de manera errónea, la interpretación de esos límites puso a prueba su capacidad de trabajo, al mismo tiempo que su competencia en el encargo y su paciencia. El desinterés de los portugueses por acordar los límites de su territorio en América unido a la indiferencia de la Corona española para concluir estas delimitaciones, provocó que los acuerdos necesarios para dar por concluidos los trabajos se dilataran durante un larguísimo periodo de tiempo. Cerca de 14 años, una vez cumplido el encargo, se 
mantuvo Azara a la espera de que le permitieran regresar a tierras españolas. Lejos de impacientarse ante tal circunstancia, decidió dedicarse al estudio y descripción de la naturaleza americana.

Formado en filosofía y artes militares, este aragonés nacido en Barbuñales (Huesca), no poseía ningún conocimiento de Historia Natural en el que apoyarse. Tampoco disponía de libros de consulta para ampliar sus conocimientos ni mantenía contacto con otros naturalistas con los que intercambiar información o reflexiones. De manera que, en una decisión más heroica que racional, armado sólo con una voluntad impenetrable, unas enormes ganas de conocer y su pasión por aquellas recónditas tierras salvajes, se dispuso a afrontar el reto que suponía el estudio de su biodiversidad. Así cuenta su mentor y traductor al francés C. A. Walckenaer sobre cuál era la intendencia de sus viajes y las condiciones en las que trascurrían sus investigaciones (Walckenaer, C.A. 1809)

Se proveia de aguardiente, cuentas de vidrio, cintas, cuchillos y otras bagatelas para ganar la amistad de los salvajes. Todo su equipaje personal consistia en algunas ropas, una hamaca, un poco de café, y un poco de la escasisima sal. Para sus acompañantes llevaba también tabaco y hierba del Paraguay (hierba mate). Todos los que le acompañaban llevaban sólo lo puesto (...).

Se levantaban una hora antes del amanecer para preparar el desayuno. Hecha esta comida, los soldados se destacaban para reunir los caballos, que andaban esparcidos por los alrededores, a veces a una legua de distancia, porque excepto los que cada uno conservaba por la noche a su lado, los otros abandonados a si mismos, pacian en completa libertad (...).

En seguida se ponian en camino, dos horas después de salir el sol. Como en estos desiertos no habia trazado camino alguno, un guia buen conocedor del pais marchaba trescientos pasos por delante (...). Después avanzaban los caballos de recambio, y los seguia el resto de la tropa, marchando asi sin detenerse hasta dos horas antes de ponerse el sol.
Se busca entonces sitio para acampar, generalmente a orillas de una laguna o riachuelo, dispersándose los hombres en procura de leña para hacer fuego y carnear las vacas necesarias para alimentar a los miembros de la expedición, tomándolas bien de las cimarronas o de las pertenecientes a las estancias de las cercanias; a falta de estas mataban a las que llevaban a retaguardia, cuando no tatuejos o armadillos que encontraban en los campos de las inmediaciones. Cuando atravesaban regiones carentes de ganado, ni los llevaban en retaguardia por falta de pastos, preparaban de antemano carne de vaca cortada en lonjas y secada al sol, que luego se comía asada.

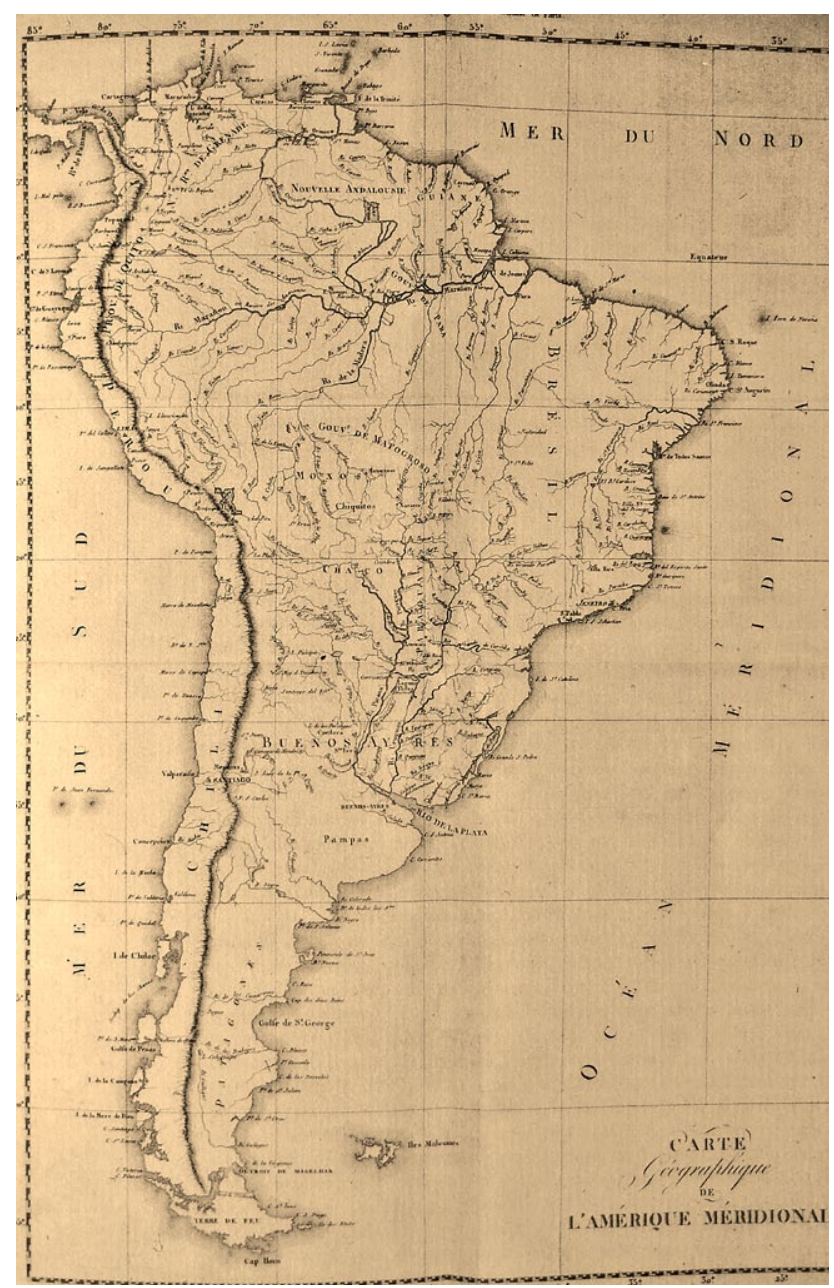

Mapa de la América Meridional. Fuente: Apuntamientos para la Historia Natural de los Páxaros del Paraguay y del Río de la Plata. Edición de Joaquín Fernández Pérez. Ejemplar No 1554. 
Antes de acampar en un sitio cualquiera era necesario tomar precauciones contra las víboras, que son con frecuencia muy numerosas. Se hacía pasear a todos los caballos en el espacio que se iba a ocupar, a fin de aplastar a los reptiles o de hacer salir a los que estuvieran ocultos en la hierba; algunas veces esta operación costaba la vida a algún caballo. Cuando se trataba de acostarse, cada individuo, provisto de un trozo de piel de vaca, la extendia por tierra. Azara era el único que tenía una hamaca, que se suspendia de dos palos o de dos árboles. Durante la noche cada uno conservaba su caballo al lado, a fin de poder huir de las fieras si era necesario. Su aproximación era siempre anunciada por los perros, que las sentían de muy lejos por el olor muy fuerte que exhalan. Con frecuencia, a pesar de las precauciones que habian tomado, se deslizaban en el campo algunas viboras; pero se ocultaban generalmente debajo de las pieles de los que dormían y permanecian tranquilas. A veces pasaban cerca y aun por encima de los hombres sin hacerles ningún mal, por que no muerden más que cuando se las inquieta.

La experiencia le habia demostrado a Don Félix que el medio más eficaz para preservarse las mordeduras de las viboras era calzar botas, pues aunque las perforan con sus dientes, el veneno no penetra jamás en la carne (...).

Las marchas diurnas se verificaban solamente en las regiones donde no habia que temer ataques de los indigenas, pero cuando se presentaba el cruce de un territorio habitado con indios hostiles, Azara tomaba otras precauciones, marchando sólo de noche y enviando en todas direcciones exploradores para reconocer el camino que habia que seguir. (...). A pesar de estas precauciones el señor Azara fue atacado muchas veces y tuvo el sentimiento de perder alguno de los suyos.

Resulta difícil hacerse una idea, desde una perspectiva actual, de las privaciones, incomodidades, peligros y esfuerzo intelectual necesarios para acometer una aventura semejante. Aun teniendo presente la proverbial capacidad de adaptación humana, en una época en la que la noción de bienestar distaba mucho de ser remotamente parecida a la nuestra, hace falta un carácter y un tesón fuera de lo común para concebir y dar cuenta de una empresa de esas dimensiones. No es posible mantener una perseverancia de tal calibre, si en el fondo la recompensa no va implícita en el propio deleite del contacto con la naturaleza. Tal vez sea esa capacidad de emoción, de disfrute ante la naturaleza, lo que mejor matice la condición del naturalista, en general, y la del propio Azara en particular. No obstante, algunos autores apuntan que sus trabajos en la América meridional no fueron más que una forma de distraer el tedio en un paraje inculto, o una forma de realizar un trabajo que fuera algún día recompensado. Para pensar de ese modo se apoyan en que en ningún pasaje de su obra aparece referencia alguna a su vinculación emocional con la naturaleza. Aun reconociendo que es curiosa la ausencia en sus escritos de algún comentario sobre la belleza de los paisajes, de la flora o la fauna que estudió, no creo que esto sea suficiente para explicar una supuesta falta de sensibilidad o afecto por la naturaleza. Se sabe, por ejemplo, que su cuarto, al que hace alusión en diferentes ocasiones, era un lugar donde las aves eran mantenidas y cuidadas con esmero. En ocasiones cuenta que se subían a su catre y le picaban las pierna para que les diera de comer. Pero, sobre todo, no es muy probable que alguien dedique voluntariamente tanto tiempo a un actividad que entrańa tal cantidad de penalidades y sacrificios, sin experimentar un considerable deleite en su realización, sólo por el hecho de que sea algún día reconocida su labor.

Azara no sólo empleó su tiempo en estudiar la fauna del continente americano, sino también en escribir sobre ella y en preparar sus publicaciones. Tal vez sus dos obras más conocidas sean Apuntamientos para la Historia Natural de los Quadrúpedos del Paraguay y del Río de la Plata (1802) y Apuntamientos para la Historia Natural de los Páxaros del Paraguay y del Río de la Plata (1805), obra esta última por la que Félix de Azara puede considerarse un excelente ornitólogo, uno de los mejores de su tiempo. Fue, sin duda, un gran observador de campo, dotado de original talento para describir las formas y los colores de las aves, además de un indagador incansable: describió 448 pájaros distintos, aunque no todos fueran especies diferentes. En la actualidad 


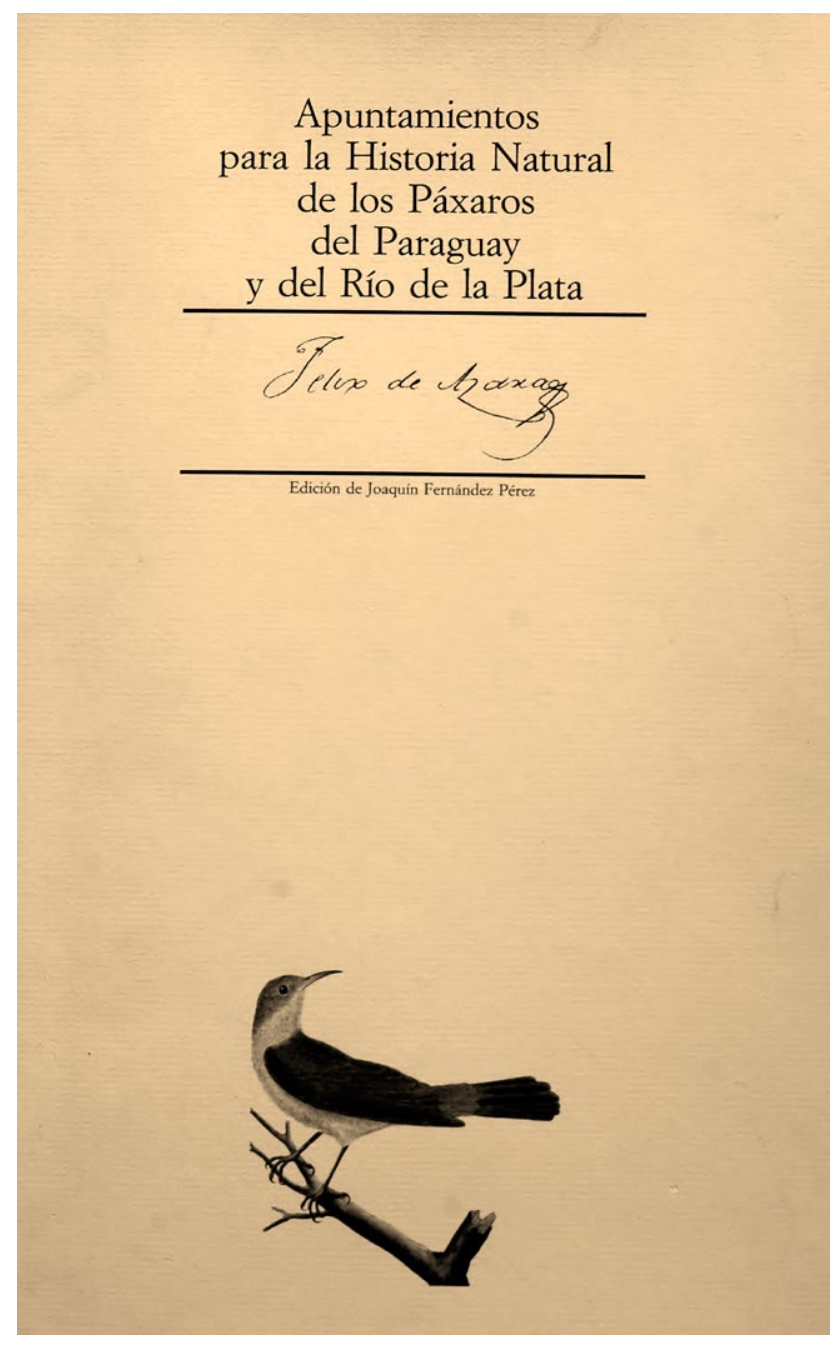

Portada del libro sobre aves de Félix de Azara. Apuntamientos para la Historia Natural de los Páxaros del Paraguay y del Río de la Plata. Edición de Joaquín Fernández Pérez. Ejemplar No 1554.

se han descritos cerca de 700 especies en Paraguay y, entre Argentina y Uruguay, en torno a 1000, lo que da idea del monumental trabajo que llevó a cabo en solitario nuestro personaje. Pero además de abundante, su legado científico es inusualmente riguroso: cuando en sus descripciones no tenía el animal delante, lo indicaba para que se tuviera en cuenta. Esta honestidad y rigor científico no era en absoluto común entre los ornitólogos de su época, lo cual, por cierto, lo solía sacar de sus casillas. Hasta tal punto se puede considerar que Azara fue un naturalista fiable, que entre los herederos de su obra se encuentra el propio Darwin, quien no siendo en absoluto proclive a citar autores de los que no tuviera cumplidas referencias, lo cita con frecuencia en algunas de sus obras, sobre todo en el Viaje de una naturalista alrededor del mundo.

Sólo dispuso Azara de una obra de referencia que pudo consultar y estudiar durante su estancia en América y sólo cuando ya llevaba en el continente más de una década: la Historia Natural del francés George-Louis Le Clerc, conde de Buffon, con el que es posible que, posteriormente, mantuviera algún contacto durante su estancia en París, pero del que no ha quedado constancia. No obstante, fue de este trabajo de donde adquirió Azara sus escasos conocimientos de Zoología mientras viajó por América; hasta tal punto fue así que se refería a Buffon como "mi autor". No obstante, esto no impidió que Azara criticara muchas de las aseveraciones del científico francés, acusándolo, en ocasiones, de trabajar con referencias bibliográficas de otros autores que, a su vez, eran erróneas. Así se explica el naturalista aragonés en el prólogo de Apuntamientos para la Historia Natural de los Quadrúpedos:

Como no he leido otra obra que la de Mr. Buffon, me he visto como forzado a preferirle en mis criticas; pero es bien fácil conocer, que no son tanto contra él, como contra Viageros y Naturalistas, de quienes copió los errores que impugno.

Las principales críticas que Azara hiciera a Buffon se centraban en lo que éste llamaba "causas de la variabilidad", haciendo referencia a factores climáticos, tróficos, etc. Como con el tiempo quedaría demostrado, los procesos de variabilidad presentan unas causas aleatorias y no siempre provocadas por las condiciones ambientales como pretendía Buffon y rechazaba Azara. Pero no sólo se interesó Azara por los temas zoológicos y botánicos. También reflexionó y escribió sobre otras disciplinas que, por entonces, ni siquiera constituían un cuerpo de conocimientos independiente; tal es el caso de la Antropología, estudiando los usos y costumbres de algunos pueblos indígenas que conoció; o sobre Biogeografía, estableciendo hábitats propios para ciertas especies de animales y plantas e incluso sobre Etología, describiendo el comportamiento de 
numerosos animales. Armado exclusivamente con unas extraordinarias dotes de observación y deducción, Azara logrará realizar aportaciones totalmente novedosas, estableciendo incluso principios básicos en algunas de estas disciplinas.

Pese al tiempo trascurrido y a las lógicas deficiencias de una obra prácticamente autodidacta en el sentido más estricto del término, los trabajos de campo del naturalista aragonés deberían estar considerados entre los grandes de nuestra Historia Natural; de este modo se podría paliar, al menos en parte, el hecho de que su nombre no figure, de manera distinguida en los anales de nuestra historia científica y cultural. No dejemos que su propio comentario se haga realidad, cuando decía que en Espańa la mejor forma de guardar un secreto es escribirlo en un libro.
Sirva este breve artículo como excusa para reivindicar la figura de un hombre que por méritos propios debería ocupar un lugar entre nuestros grandes científicos, al tiempo que para reclamar la condición de naturalista que, sin duda, alcanzó.

\section{REFERENCIAS}

Azara, F. (1992). Apuntamientos para la Historia Natural de los Páxaros del Paraguay y del Río de la Plata. Edición de Joaquín Fernández Pérez. Comisión Internacional de Ciencia y Tecnología. Madrid.

Azara, F. (1969). Viajes por la América Meridional. Madrid, Colección Austral.

Walckenaer, C.A. (1809). Voyages dans L'Amerique Méridionale par Don Félix de Azara. Paris. Dentu 